\title{
Os impactos da abertura comercial e do investimento direto sobre o investimento doméstico
}

\author{
Leilyanne Viana Nogueira \\ Doutoranda - Universidade Federal do Ceará (UFC/CAEN) \\ Endereço: Av. da Universidade, 2700 - $2^{\circ}$ andar - Benfica - Fortaleza - Ceará \\ CEP: 60020-181 - E-mail: leilyviana@hotmail.com
}

\section{Roberto Tatiwa Ferreira}

Professor - Universidade Federal do Ceará (UFC/CAEN)

Endereço: Av. da Universidade, 2700 - $2^{\circ}$ andar - Benfica - Fortaleza - Ceará

CEP: 60020-181 - E-mail: rtf2@uol.com.br

Recebido: 17/04/2016. Aceite: 20/04/2017.

\section{Resumo}

O principal objetivo deste estudo é estimar os efeitos do comércio e do investimento direto estrangeiro (IDE) sobre o investimento doméstico e testar se esses efeitos dependem do nível de renda e do desenvolvimento financeiro dos países. Para isso, o presente estudo modifica o modelo de painel dinâmico com efeito limiar de Kremer, Bick e Nautz (2013) - permitindo um número maior de regressores endógenos - e utiliza uma base de dados composta por 95 países no período de 1985 a 2013. Os resultados sugerem que o comércio afeta positivamente o investimento doméstico. Por outro lado, o efeito do IDE sobre o investimento doméstico é negativo em ambos os regimes de renda e nos países de baixo desenvolvimento financeiro.

\section{Palavras-Chave}

Investimento. Abertura comercial. Dados em painel. Efeito limiar.

\begin{abstract}
The aim of this study is to estimate the effects of trade and foreign direct investment (FDI) on domestic investment and test whether these effects depend on the level of income and financial development of countries. For this, the present study modifies the dynamic panel models with threshold effect proposed by Kremer, Bick and Nautz (2013) allowing a greater number of endogenous regressors and uses a data base composed of 95 countries in the period from 1985 to 2013. The results suggest that trade positively affects domestic investment. However, the effect of FDI on domestic investment is negative in both income regimes and in low financial development countries.
\end{abstract}

\section{Keywords}

Investment. Opennes. Panel data. Threshold effect.

\author{
JEL Classification \\ O16. O50. C23. C24.
}




\section{Introdução}

O padrão de vida dos indivíduos depende diretamente da trajetória de crescimento econômico de longo prazo do país. Segundo Barro e Sala-iMartin (2004), é importante estudar essas trajetórias de crescimento, porque mesmo pequenas diferenças nas taxas de crescimento de longo prazo, quando acumuladas ao longo dos anos, produzem efeitos consideráveis nos padrões de bem-estar dos indivíduos. Considerando a importância do crescimento econômico, é imprescindível, portanto, compreender seus fatores determinantes. Além disso, essa compreensão também é fundamental para a formatação de políticas.

Nesse sentido, o estímulo à abertura comercial e a oferta de incentivos à atração de investimento direto estrangeiro são políticas comumente recomendadas para os países em desenvolvimento, embora, nos modelos teóricos e nos estudos empíricos, não haja consenso a respeito do impacto da abertura sobre o crescimento econômico. Nessa linha de pesquisa, uma questão importante é se o efeito da abertura comercial e financeira sobre o crescimento se dá, principalmente, pela via de acumulação de capital físico e humano ou ocorre por meio de elevação na produtividade total dos fatores.

O estudo de Kim, Lin e Suen (2013) foca exatamente no impacto do comércio e do investimento direto estrangeiro sobre o investimento doméstico. Especificamente, os autores investigam se os efeitos da globalização sobre o investimento doméstico dependem da capacidade social do país, relacionada ao nível de renda per capita inicial, ao estoque de capital humano inicial, ao grau de desenvolvimento financeiro e às instituições políticas. Usando a abordagem de regressão threshold com variável instrumental para dados de cross-section de 85 países, os autores encontram evidências de que o comércio afeta negativamente o investimento em países com baixa capacidade social, isto é, com baixo nível de capital humano, sistemas financeiros menos desenvolvidos e mais corruptos. Por outro lado, os resultados indicam que o comércio é positivamente correlacionado com o investimento em países de alta capacidade social. Além disso, o efeito do IDE sobre o investimento é positivo nos países de baixa capacidade social e negativo nos países com alta capacidade social. 
Motivado pela análise de Kim, Lin e Suen (2013), o objetivo principal deste estudo é investigar se os efeitos do comércio e do investimento direto estrangeiro sobre o investimento doméstico dependem do nível de renda per capita e do grau de desenvolvimento financeiro dos países. Além disso, a principal contribuição deste artigo em relação ao de Kim, Lin e Suen (2013) é analisar essa relação por meio de métodos que podem fornecer evidências empíricas mais robustas. Para isso, o presente trabalho utiliza modelos de dados em painel com efeito limiar ${ }^{1}$ (threshold) aplicado a uma base de dados mais ampla. Há várias vantagens em utilizar dados em painel em relação a modelos com dados de corte transversal (cross-sections). ${ }^{2}$ Ademais, este trabalho adapta o modelo dinâmico de painel com efeito limiar de Kremer, Bick e Nautz (2013) para permitir um número maior de regressores endógenos.

A base de dados é formada por um conjunto de 95 países no período de 1985 a 2013, para estimar, em princípio, uma regressão linear do investimento doméstico contra uma medida de abertura comercial e um indicador de abertura financeira. São usados como controles adicionais a renda per capita inicial e o grau de desenvolvimento financeiro dos países. Além disso, a fim de investigar se efeitos threshold de renda e de desenvolvimento financeiro importam na determinação do efeito do comércio e do investimento direto estrangeiro sobre o investimento doméstico, estima-se um modelo de dados em painel não linear.

O trabalho contém mais quatro seções. Na segunda seção, são apresentados os aspectos teóricos e empíricos das relações de interesse: investimento doméstico versus abertura comercial e investimento doméstico versus investimento direto estrangeiro. A terceira seção apresenta a base de dados utilizada, a abordagem econométrica e a análise descritiva. Na quarta seção, são discutidos os resultados. Por fim, a última seção traz as considerações finais.

1 As variáveis podem exibir outras formas de não linearidade, como quebras estruturais. Entretanto, até o momento, não há procedimentos para estimar modelos em painel com efeito threshold e quebras estruturais. Por outro lado, Carrasco (2002) mostra que modelos com efeito threshold podem capturar quebras estruturais, mas testes para quebras estruturais não têm força se a variável analisada possuir efeito threshold.

2 Wooldridge (2002) apresenta essas vantagens do ponto de vista da teoria econométrica, enquanto Barro e Sala-i-Martin (2004) mostram algumas dessas possíveis vantagens na análise do crescimento econômico. 


\section{Revisão de literatura}

\subsection{Investimento doméstico versus abertura comercial}

Uma questão importante na literatura de crescimento econômico é a relevância da abertura comercial. O comércio internacional acelera ou retarda o crescimento dos países que se abrem para o resto do mundo? Mais ainda, o efeito da abertura se dá via formação bruta de capital ou por meio de outros determinantes do crescimento?

Conforme Harrison (1996), nos modelos de crescimento endógeno, a política comercial afeta o crescimento de longo prazo por meio do seu impacto em progresso tecnológico. Isso porque a abertura comercial possibilita acesso a insumos importados, que contêm nova tecnologia; aumenta o tamanho efetivo do mercado para os produtores; e afeta a especialização do país numa produção intensiva em pesquisa. Entretanto, como destaca Schumpeter, o aumento da competição pode desencorajar a inovação ao diminuir os lucros esperados.

A literatura aponta ainda os seguintes benefícios da abertura comercial para o crescimento econômico: spillovers tecnológicos; transmissão internacional de conhecimento; maior facilidade na obtenção de eficiência alocativa; especialização na produção de acordo com as vantagens comparativas; ganhos de eficiência em virtude da maior escala dos mercados; e incentivo à adoção de política disciplinada de gestão macroeconômica (Wacziarg 2001). Por outro lado, Kim, Lin e Suen (2013) destacam que, na presença de imperfeições institucionais e de mercado, a abertura comercial pode contribuir para uma subutilização de recursos humanos e de capital, concentração em atividades econômicas extrativas ou especialização em setores de baixa tecnologia. Dessa forma, a abertura influenciaria negativamente a formação bruta de capital e o crescimento econômico.

Adaptando o modelo de crescimento endógeno de Rebelo (1991) para uma economia aberta, Lee (1995) investiga se os países menos desenvolvidos devem focar nas atividades em que possuem vantagens comparativas ou devem proteger indústrias-chave para o crescimento. $\mathrm{O}$ autor verifica empiricamente que o comércio internacional, ao fornecer bens de capital estrangeiros relativamente mais baratos, aumenta a eficiência da acumulação de capital e assim a taxa de crescimento da renda, principalmente, para os países em desenvolvimento. 
De forma semelhante, o modelo teórico de Baldwin e Seghezza (1996) analisa a relação entre comércio e crescimento, focando no investimento. Os autores supõem que o setor de bens de capital usa insumos que podem ser importados, de modo que os preços de importados e de substitutos locais afetam o custo do novo capital. Sendo assim, a proteção doméstica aumenta o custo de produzir novos bens de capital e tende a diminuir o retorno e a taxa de investimento. Para uma amostra de países exportadores de manufaturados, os autores constatam que a proteção doméstica afeta negativamente o investimento e, logo, reduz o crescimento econômico.

Por sua vez, Eicher (1999) examina os ganhos dinâmicos do comércio para países atrasados e países líderes. O autor destaca que o capital humano e o progresso tecnológico são endógenos e seus respectivos custos e benefícios de acumulação interagem, induzindo o comércio a produzir os ganhos dinâmicos que reduzem os gaps tecnológicos e de crescimento. Isso porque ao abrir o mercado de bens para o resto do mundo, o país atrasado experimenta uma contração estática inicial do seu setor de alta tecnologia que é intensivo em trabalho qualificado, o que diminui o salário relativo (os custos) dos trabalhadores qualificados e libera recursos para o desenvolvimento de pesquisa e a melhoria da educação. O resultante aumento dinâmico na oferta de trabalhadores qualificados e na taxa de inovação doméstica permite que o país atrasado reduza o gap em tecnologia, dotação de fatores e taxas de crescimento.

No final desta seção, o Quadro 1 sintetiza os resultados de alguns estudos que investigam empiricamente a relação entre comércio e investimento.

\subsection{Investimento doméstico versus investimento direto estrangeiro}

O IDE beneficia um país receptor de recursos estrangeiros porque: (1) fornece um mecanismo de transferência de tecnologia, que não é obtido por meio de investimentos financeiros nem pelo comércio de bens e serviços; (2) incentiva o desenvolvimento de capital humano; e (3) possibilita a arrecadação de tributos dos lucros gerados pelo capital transferido. Além disso, o IDE favorece a firma estrangeira, uma vez que facilita a exploração de economias de escalas na produção e em atividades de pesquisa e desenvolvimento (Feldstein 2000). 
Mas em relação ao investimento doméstico, o IDE atua como complemento ou substituto? Na literatura, não há consenso a respeito dessa relação, visto que razoáveis argumentos teóricos são apresentados para ambas as hipóteses, de complementação e de substituição entre IDE e investimento doméstico. Da mesma forma, os estudos empíricos também divergem quanto à relação entre as duas formas de investimento.

De Mello (1999) ressalta que o IDE pode elevar a produtividade, estimular o investimento doméstico e o progresso tecnológico, pois se espera que IDE promova a incorporação de novos insumos e de tecnologias estrangeiras na função de produção do país receptor de recursos e aumente seu estoque de conhecimento, por meio de capacitação profissional, aquisição de habilidades e rearranjos organizacionais.

Usando dados de 32 países no período de 1970 a 1990, De Mello (1999) encontra que o grau de substituição entre o estoque de capital incorporado em velhas tecnologias (investimento doméstico) e em novas tecnologias (IDE) parece ser maior em economias tecnologicamente avançadas. Possivelmente, na presença de IDE, a taxa de obsolescência tecnológica do estoque de capital antigo é crescente nas economias avançadas. Além disso, as economias em desenvolvimento são menos eficientes no uso das novas tecnologias e têm dificuldade de assimilar melhorias intensivas em tecnologia e capital, o que favorece a complementaridade entre o investimento doméstico e o IDE.

Outra possível forma de complementação entre o investimento doméstico e o IDE ocorre quando IDE estimula relações de produção backward ou forward no país receptor do investimento (Van Loo 1977; Markusen e Venables 1999 apud Wang 2010). Um exemplo desse tipo de relação citado em Wang (2010) é o aumento da demanda por insumos intermediários produzidos domesticamente, resultado da entrada de uma empresa multinacional produtora de bens finais, o que levaria a um crescimento na taxa de retorno na indústria de insumos e, portanto, a um aumento no investimento nessa indústria, possivelmente com aumento do número de firmas domésticas produzindo tais insumos.

Wen (2007) argumenta ainda que o IDE pode criar um efeito demonstração sobre a direção do investimento. Esse efeito resultaria das ações de investidores estrangeiros, que captam melhor as condições de mercado no país receptor do investimento, têm mais conhecimento de gestão e, 
portanto, são mais capazes de identificar oportunidades de investimento para maximização de lucro. Desse modo, o IDE pode então aumentar a eficiência ao sinalizar as direções corretas para o investimento.

Por sua vez, Easterly (1993) estuda os efeitos de políticas de diferenciação de tributação e tarifas e controle de preços sobre o crescimento de longo prazo, por meio de um modelo de crescimento endógeno com dois tipos de capital. O autor verifica que a concessão de subsídios para um tipo de capital, financiado pela taxação do outro tipo de capital, diminui a taxa de crescimento. Constata também que o investimento no capital subsidiado torna-se mais atrativo e ocorre a substituição do capital taxado pelo capital subsidiado. Dessa forma, como destacam Kim, Lin e Suen (2013), a política de tratamento fiscal diferenciado e a oferta de outros incentivos para atrair o IDE podem gerar fortes distorções entre os retornos dos capitais estrangeiro e doméstico, favorecendo a substituição das duas formas de investimento.

Van Loo (1977) também ressalta que o acesso a tecnologias mais avançadas, melhor gestão e privilégios de impostos e importação garantem ao IDE uma vantagem comparativa em relação ao investimento doméstico. Essas são, portanto, as possíveis causas do efeito substituição entre os dois tipos de investimento. O efeito crowding-out também pode ocorrer se as empresas multinacionais financiarem seus investimentos por meio de empréstimos tomados no mercado de crédito do país receptor do IDE, o que pode elevar a taxa de juros impactando negativamente o investimento doméstico (Harrison e Mcmillan 2003 apud Wang 2010).

O Quadro 1 apresenta as principais conclusões de alguns outros estudos que analisam a relação entre IDE e investimento. 
Quadro 1 - Evidências empíricas sobre as relações comércio-investimento e IDEinvestimento

\begin{tabular}{|c|c|c|c|}
\hline Autor & Período & Metodologia & Conclusões \\
\hline $\begin{array}{l}\text { Levine e } \\
\text { Renelt } \\
(1992)\end{array}$ & 1974 a 1989 & $\begin{array}{l}\text { - Dados de } 119 \text { países. } \\
\text { - Usam uma variante de extreme-bounds } \\
\text { analysis de Leamer (1983). }\end{array}$ & $\begin{array}{l}\text { - Correlação positiva e robusta entre investi- } \\
\text { mento (\% do PIB) e comércio (\% do PIB). } \\
\text { - Políticas comerciais são importantes somen- } \\
\text { te se possibilitam maior acesso a bens de } \\
\text { investimento. }\end{array}$ \\
\hline $\begin{array}{c}\text { Harrison } \\
(1996)\end{array}$ & 1960 a 1988 & $\begin{array}{l}\text { - Usa } 7 \text { medidas de abertura comercial. } \\
\text { - Painel de dados de } 51 \text { países. } \\
\text { - Estimação de efeitos fixos. }\end{array}$ & $\begin{array}{l}\text { - Relação positiva e robusta entre comércio (\% } \\
\text { do PIB) e investimento (\% do PIB). } \\
\text { - Não encontra relação robusta ou consistente } \\
\text { entre investimento (\% do PIB) e qualquer outra } \\
\text { medida de abertura. }\end{array}$ \\
\hline $\begin{array}{l}\text { Wacziarg } \\
(2001)\end{array}$ & 1970 a 1989 & $\begin{array}{l}\text { - Dados de } 57 \text { países. } \\
\text { - Usa uma extensão para dados em painel } \\
\text { do método de MQ3E de Zellner e Theil } \\
\text { (1962). }\end{array}$ & $\begin{array}{l}\text { - A abertura comercial afeta o crescimento, } \\
\text { principalmente, elevando o investimento do- } \\
\text { méstico (\% do PIB). }\end{array}$ \\
\hline $\begin{array}{c}\text { De Mello } \\
(1999)\end{array}$ & 1970 a 1990 & $\begin{array}{l}\text { - Dados de } 32 \text { países, membros e não- } \\
\text { membros da OCDE. } \\
\text { - A partir das séries temporais dos países, } \\
\text { estima um modelo VAR bivariado. } \\
\text { - Para os dados em painel, usa o estimador } \\
\text { de efeitos fixos. }\end{array}$ & $\begin{array}{l}\text { - O IDE tem um impacto positivo de longo pra- } \\
\text { zo sobre a acumulação de capital no Panamá } \\
\text { e em Serra Leoa. } \\
\text { - Os resultados das estimações de efeitos fixos } \\
\text { sugerem um efeito dominante de complemen- } \\
\text { taridade entre IDE e investimento doméstico. }\end{array}$ \\
\hline $\begin{array}{l}\text { Wen } \\
(2007)\end{array}$ & 1995 a 2001 & - Um painel de dados regionais da China. & $\begin{array}{l}\text { - Efeito substituição entre IDE e investimento } \\
\text { doméstico na região leste da China. }\end{array}$ \\
\hline $\begin{array}{l}\text { Lean e Tan } \\
\quad(2011)\end{array}$ & 1970 a 2009 & $\begin{array}{l}\text { - Dados da Malásia. } \\
\text { - Modelo vetor de correção de erro. }\end{array}$ & $\begin{array}{l}\text { - O IDE impacta positivamente o investimento } \\
\text { doméstico. }\end{array}$ \\
\hline $\begin{array}{l}\text { Van Loo } \\
(1977)\end{array}$ & 1948 a 1966 & $\begin{array}{l}\text { - Dados do Canadá. } \\
\text { - Estimação por MQO e por MQ2E. }\end{array}$ & $\begin{array}{l}\text { - Um aumento do IDE produz um aumento no } \\
\text { investimento total (o efeito direto positivo é re- } \\
\text { duzido pelos efeitos indiretos negativos). }\end{array}$ \\
\hline $\begin{array}{l}\text { Wang } \\
(2010)\end{array}$ & 1970 a 2004 & $\begin{array}{l}\text { - Dados de } 50 \text { países (desenvolvidos (DC) } \\
\text { e menos desenvolvidos (LCD)). } \\
\text { - Painel não balanceado. } \\
\text { - Estimação por efeitos aleatórios, por efei- } \\
\text { tos fixos e por GMM Arellano-Bond. }\end{array}$ & $\begin{array}{l}\text { - O IDE contemporaneamente substitui o in- } \\
\text { vestimento doméstico nos DCs e tem efeito } \\
\text { neutro nos LCDs. O efeito acumulado (con- } \\
\text { temporâneo e defasado) do IDE é positivo nos } \\
\text { LCDs e neutro nos DCs. }\end{array}$ \\
\hline $\begin{array}{c}\text { Kim e Seo } \\
(2003)\end{array}$ & 1985 a 1999 & $\begin{array}{l}\text { - Dados da Coreia. } \\
\text { - Modelo vetor autorregressivo, funções } \\
\text { impulsos resposta e decomposição da va- } \\
\text { riância. }\end{array}$ & $\begin{array}{l}\text { - Efeito estatisticamente insignificante do IDE } \\
\text { sobre o investimento doméstico. }\end{array}$ \\
\hline
\end{tabular}

Fonte: Elaboração própria. 


\section{Metodologia}

\subsection{Base de dados}

Os dados utilizados foram extraídos da base de Indicadores de Desenvolvimento Mundial do Banco Mundial e foram organizados num painel não balanceado de 95 países no período de 1985 a 2013. ${ }^{3}$ A amostra é constituída por 23 países de alta renda que são membros da OCDE, 12 de alta renda não membros da OCDE, 25 de renda média superior, 21 de renda média inferior e 14 de baixa renda. A lista de países, sua classificação quanto à renda, ${ }^{4}$ a média dos indicadores utilizados por país e o número de períodos estão apresentados no Apêndice A.

A variável dependente de interesse é o investimento doméstico, medido pela formação bruta de capital como proporção do PIB. Destaca-se que a formação bruta de capital corresponde a investimento em ativos fixos da economia mais variações líquidas no nível de estoques. Seguindo o estudo de Kim, Lin e Suen (2013), subtrai-se de investimento doméstico as entradas líquidas de investimento direto estrangeiro, a fim de evitar dupla contagem.

O grau de abertura comercial é medido pela razão entre a soma das exportações e importações de bens e serviços e o PIB. Por sua vez, as entradas líquidas de investimento direto estrangeiro como proporção do PIB são utilizadas como proxy de abertura financeira. Essa variável é descrita na base de dados do Banco Mundial como as entradas líquidas de investimento para adquirir uma participação duradoura na gestão (10\% ou mais do

3 Esse painel não balanceado foi usado na abordagem de regressão com efeito limiar. A amostra inicial era constituída por 98 países. Utilizando o procedimento de Billor et al. (2000) para checar outliers na variável dependente, detectou-se dados discrepantes em três países: Guiné Equatorial (país 30), Lesoto (país 51) e Suriname (país 83), que foram excluídos do conjunto de dados. A evolução da variável dependente de cada país pode ser observada nos gráficos apresentados no Apêndice B. Considerando ainda a disponibilidade de informação, para a estimação do modelo linear, Equação (1), foi utilizado um painel balanceado, formado por dados de 85 países para o período de 1985 a 2012. Esses 85 países são os países do painel não balanceado excluídos 13 países (Argentina, Barbados, Canadá, Chipre, Fiji, Israel, Malta, Nova Zelândia, Ruanda, Síria, Togo, Trinidad e Tobago, Zimbabwe) mais Belize, Macau e Tonga.

4 Seguindo a classificação do Banco Mundial, as economias são divididas em quatro grupos de renda: baixa, média inferior, média superior e alta. A renda é medida usando a renda nacional bruta (RNB) per capita, em dólares dos EUA, convertida da moeda local por meio do método Atlas do Banco Mundial. Os países são reclassificados em $1^{\circ}$ de julho de cada ano, com base na estimativa da sua RNB per capita para o ano civil anterior. Neste trabalho, usou-se a classificação de 2013, cujos intervalos para a RNB per capita são: baixa renda $(\leq 1.045,00)$; renda média inferior $(1.046,00-4.125,00)$; renda média superior (4.126,00-12.745,00); e alta renda (> 12.745,00). 
capital votante) de uma empresa num país estrangeiro, correspondendo à soma do capital social, reinvestimento dos lucros e outros capitais de longo prazo ou de curto prazo, registrados no balanço de pagamentos. São consideradas também duas outras variáveis de controle: o PIB per capita real inicial, que é medido em dólares de 2005 e corresponde ao PIB per capita real do período em $t-1$, e uma medida de desenvolvimento financeiro, equivalente aos recursos financeiros ofertados pelos bancos ao setor privado como percentual do PIB. As variáveis utilizadas nas estimações estão descritas no Quadro 2.

Quadro 2 - Lista de variáveis

\begin{tabular}{|l|l|}
\hline Variável & \multicolumn{1}{|c|}{ Descrição } \\
\hline FBK & Formação bruta de capital (\% do PIB) \\
\hline OPEN & Soma de exportações e importações de bens e serviços (\% do PIB) \\
\hline IDE & Investimento direto estrangeiro (\% do PIB) \\
\hline PIB pcinicial & PIB per capita do ano anterior (constante em US\$ 2005) \\
\hline DF & Crédito interno ao setor privado ofertado pelos bancos (em \% do PIB) \\
\hline
\end{tabular}

Fonte: Elaboração Própria.

\subsection{Abordagem econométrica}

A fim de investigar o efeito do comércio e do investimento direto estrangeiro sobre o investimento doméstico dos países, considera-se, inicialmente, o seguinte modelo básico:

$$
F B K_{i t}=\mu_{i}+\alpha_{0}+\beta_{1} \text { open }_{i t}+\beta_{2} I D E_{i t}+\varphi^{\prime} w_{i t}+\varepsilon_{i t}
$$

em que $i=1, \ldots, N$ representa o país e $t=1, \ldots, T$, o tempo; $\mu_{i}$ é o efeito fixo específico do país; $w_{i t}$ é um vetor de variáveis de controle; e $\varepsilon_{i t}$ é o termo de erro. Os parâmetros desse modelo linear serão estimados por um estimador de mínimos quadrados de dois estágios (MQ2E) para dados em painel, para fins de comparação com o modelo não linear de interesse. As variáveis de controle em $w_{i t}$ são o PIB per capita real inicial e a medida de desenvolvimento financeiro. Além disso, será aplicado o teste de especificação de Hausman para decidir entre o estimador de efeitos fixos ou de efeitos aleatórios. 
Para averiguar se thresholds de renda per capita inicial e de grau de desenvolvimento financeiro dos países são importantes na determinação dos efeitos da abertura comercial e da abertura financeira sobre o investimento doméstico, estima-se o seguinte modelo não linear de dois regimes: ${ }^{5}$

$$
\begin{gathered}
F B K_{i t}=\mu_{i}+\beta_{11} \text { OPEN }_{i t} I\left(q_{i t} \leq \gamma\right)+\beta_{21} I D E_{i t} I\left(q_{i t} \leq \gamma\right)+\delta_{1} I\left(q_{i t} \leq \gamma\right) \\
+\beta_{12} \text { OPEN }_{i t} I\left(q_{i t}>\gamma\right)+\beta_{22} I D E_{i t} I\left(q_{i t}>\gamma\right)+\varphi^{\prime} w_{i t}+\varepsilon_{i t}
\end{gathered}
$$

onde $I($.$) é uma função indicadora do regime, definido pela variável thre-$ shold exógena $q_{i t}$; e $\gamma \in \Gamma$ é o parâmetro threshold, com subconjunto estrito do suporte de $q_{i t}$ dado por $\Gamma$.

De acordo com Kim, Lin e Suen (2013), os regressores OPEN e IDE são provavelmente endógenos, devido a efeitos feedbacks do investimento doméstico ou devido a efeitos comuns de variáveis omitidas nas relações. Considerando a possível endogeneidade desses regressores, os autores utilizam instrumentos geográficos nacionais, como população, área territorial, área sem litoral, latitude, diversidade étnica, entre outros. Uma vez que esses instrumentos são, em geral, invariantes no tempo, e neste trabalho, os dados estão organizados em painel, optou-se por utilizar as variáveis explicativas endógenas defasadas como instrumentos. Para tanto, verificase a validade desses instrumentos por meio do teste de Hansen-Sargan, cuja hipótese nula estabelece que os instrumentos não são correlacionados com o termo de erro. Além disso, na regressão do $1^{\circ}$ estágio, verifica-se a significância conjunta dos instrumentos.

Uma vez que o conjunto de informação é um painel de dados e os regressores OPEN e IDE podem ser endógenos, a estimação da regressão threshold seguirá a proposta de Kremer, Bick e Nautz (2013). Esses autores desenvolvem um modelo threshold de painel dinâmico que se baseia no modelo threshold de painel estático de Hansen (1999) e no modelo threshold de cross-sectional de estimação de variável instrumental de Caner e Hansen (2004).

5 O modelo dinâmico de painel com efeito limiar de Kremer, Bick e Nautz (2013) permite a estimação e o teste de significância de um valor threshold, que divide a amostra de dados em dois regimes. Dessa forma, a metodologia utilizada neste artigo limita a investigação da existência de mais regimes. Os resultados devem, portanto, ser interpretados considerando tal limitação. 
No modelo de Kremer, Bick e Nautz (2013), são investigados os efeitos de thresholds de inflação sobre o crescimento econômico de longo prazo para dois conjuntos de países - industrializados e não industrializados, permitindo a presença de regressores endógenos. No exercício empírico realizado por esses autores, a inflação é a variável threshold e também o regressor dependente do regime, enquanto a renda per capita inicial é a única variável de controle endógena.

Neste artigo, a existência de thresholds de renda e de desenvolvimento financeiro nas relações entre investimento doméstico, abertura comercial e abertura financeira é investigada com base numa modificação do modelo threshold de painel de Kremer, Bick e Nautz (2013), enquanto Kim, Lin e Suen (2013) estudam o problema a partir da abordagem de regressão threshold de variável instrumental de dados em corte transversal de Caner e Hansen (2004). Dessa forma, a principal contribuição deste artigo em relação ao de Kim, Lin e Suen (2013) é a utilização de modelos de dados em painel com efeito limiar aplicado a uma base de dados mais ampla. Uma contribuição secundária deste estudo consiste na adaptação do modelo de Kremer, Bick e Nautz (2013) a fim de considerar duas variáveis explicativas endógenas, abertura comercial e investimento direto estrangeiro, que são também variáveis dependentes do regime. Além disso, as variáveis thresholds utilizadas são variáveis de controle exógenas não dependentes do regime.

Para detalhamento do procedimento de estimação, considere o seguinte modelo threshold de painel:

$$
y_{i t}=\mu_{i}+\beta_{1}^{\prime} z_{i t} I\left(q_{i t} \leq \gamma\right)+\beta_{2}^{\prime} z_{i t} I\left(q_{i t}>\gamma\right)+\varepsilon_{i t}
$$

onde $z_{i t}$ é um vetor $m$ dimensional de variáveis explicativas que pode incluir valores defasados de $y$ e outras variáveis endógenas. Considere a partição de $z_{i t}$ em dois subconjuntos: $z_{1 i t}$, que representa as variáveis exógenas não correlacionadas com $\varepsilon_{i t}$; e $z_{2 i t}$, o subconjunto das variáveis endógenas correlacionadas com $\varepsilon_{i t}$. Considere ainda que existem $k \geq m$ variáveis instrumentais $x_{i t}$ (incluindo as variáveis exógenas incluídas na regressão).

O primeiro passo consiste em transformar os dados de modo que os efeitos individuais $\mu_{i}$ sejam eliminados. Conforme Kremer, Bick e Nautz (2013), a transformação de desvios ortogonais forward de Arellano e Bover (1995) é 
adequada para esse modelo threshold de painel, visto que elimina os efeitos fixos sem violar as suposições de distribuição fundamentais em Hansen (1999) e Caner e Hansen (2004). Essa transformação consiste em subtrair de cada observação a média de todas as futuras observações disponíveis de uma variável. Por exemplo, o termo de erro transformado via desvios ortogonais forward tem a seguinte configuração:

$$
\varepsilon_{i t}^{*}=\sqrt{\frac{T-t}{T-t+1}}\left[\varepsilon_{i t}-\frac{1}{T-t}\left(\varepsilon_{i(t+1)}+\cdots+\varepsilon_{i T}\right)\right]
$$

De acordo com Kremer, Bick e Nautz (2013), essa transformação não altera a estrutura de correlação dos termos de erro, ou seja,

$$
\operatorname{Var}\left(\varepsilon_{i}\right)=\sigma^{2} I_{T} \Rightarrow \operatorname{Var}\left(\varepsilon_{i}^{*}\right)=\sigma^{2} I_{T-1}
$$

Sendo assim, os autores destacam que o procedimento de estimação derivado por Caner e Hansen (2004) para o modelo cross-sectional pode ser utilizado no modelo em painel representado pela Equação (3).

Os parâmetros são estimados sequencialmente. Após a transformação dos dados, o próximo passo é estimar, por mínimos quadrados, a regressão da forma reduzida, isto é, regressar as variáveis endógenas contra o conjunto de instrumentos, $z_{2 i t}=\pi^{\prime} x_{i t}+\mu_{i t}$. Então, os valores previstos das variáveis endógenas, $\hat{z}_{2 i t}$, substituem $z_{2 i t}$ na equação estrutural. Para cada $\gamma \in \Gamma$, estima-se a Equação (3) por MQO e computa-se a soma dos quadrados dos resíduos, $S(\gamma)$. O estimador de MQ2E do parâmetro threshold é o valor que minimiza a soma dos quadrados dos resíduos, isto é,

$$
\hat{\gamma}=\operatorname{argmin} S_{n}(\gamma)
$$

Caner e Hansen (2004) destacam que, como produto da estimação, obtém-se a seguinte estatística de razão de verossimilhança do teste da hipótese nula $H_{0}: \gamma=\gamma_{0}$ :

$$
L R_{n}(\gamma)=n \frac{S_{n}-S_{n}(\hat{\gamma})}{S_{n}(\hat{\gamma})}
$$


Uma vez que $\gamma$ é estimado, divide-se a amostra em duas subamostras de acordo com a função indicadora $I\left(q_{i t} \leq \gamma\right)$ e $I\left(q_{i t}>\gamma\right)$. Então, os parâmetros da equação estrutural podem ser estimados por MQ2E ou GMM separadamente em cada subamostra.

Hansen (2000) propõe construir intervalos de confiança para o parâmetro threshold baseados na estatística de razão de verossimilhança $L R_{n}(\gamma)$. Para tanto, denote $\mathrm{C}$ o nível de confiança assintótico desejado e $c$, o valor crítico associado ao nível de confiança $\mathrm{C}$, em que:

$$
c(z)=-2 \ln (1-\sqrt{z})
$$

Os intervalos de confiança assintóticos para $\gamma$ são construídos do seguinte modo:

$$
\widehat{\Gamma}=\left\{\gamma: L R_{n}(\gamma) \leq c\right\}
$$

Graficamente, para determinar a região $\widehat{\Gamma}$, pode-se plotar a razão de verossimilhança $L R_{n}(\gamma)$ contra $\gamma$ e traçar uma linha reta em $c$. Destaca-se que a razão de verossimilhança é identicamente zero em $\gamma=\hat{\gamma}$.

\subsection{Análise descritiva}

Na Tabela 1, observa-se que, no período de 1985 a 2013, os grupos de países de renda média superior e de alta renda membros da OCDE apresentaram, em média, os maiores níveis de investimento doméstico como proporção do PIB. Por sua vez, o investimento doméstico médio nos países de alta renda não membros da OCDE, de renda média inferior e de baixa renda equivale, respectivamente, a $88 \%, 85 \%$ e $77 \%$ da média de investimento dos países de renda média superior. Ressalta-se também que, no grupo de renda média superior, há maior dispersão dos países quanto ao nível de investimento doméstico, enquanto a variabilidade do investimento médio é menor no grupo de alta renda OCDE. Destaca-se a evolução do investimento doméstico na China (país 19) e na Coreia (país 50).

Em relação à abertura comercial, a Tabela 1 indica que, em média, os países da amostra que mais transacionam com o resto do mundo (ponderado pelo PIB) pertencem ao grupo de alta renda não membros da OCDE. Em 
seguida, sobressaem-se os países de renda média superior. Por sua vez, os países com menores volumes de exportações e importações (em \% do PIB) pertencem ao grupo de baixa renda. Ressalta-se que a medida do desvio -padrão indica maior dispersão nos grupos de alta renda não-OCDE e de renda média superior. Para esses grupos, destacam-se Cingapura (país 75) e Malásia (país 54) com maiores volumes de comércio, e Uruguai (país 95) e Brasil (país 12) com os menores níveis de abertura.

Com respeito às entradas líquidas de investimento direto estrangeiro como proporção do PIB, as médias por grupo de países na Tabela 1 sugerem que os países de alta renda não participantes da OCDE e os de renda média superior são os destinos principais de recursos estrangeiros. Por sua vez, a média mais baixa do grupo de alta renda da OCDE pode indicar que esses países são os principais ofertantes de recursos para IDE.

Tabela 1 - Estatísticas descritivas

\begin{tabular}{|c|c|c|c|c|c|c|}
\hline \multirow{2}{*}{\multicolumn{2}{|c|}{$\begin{array}{l}\text { Variáveis } \\
\text { Baixa renda }\end{array}$}} & \multicolumn{5}{|c|}{ Grupos de países } \\
\hline & & \multirow{2}{*}{$\begin{array}{r}\text { Baixa Renda } \\
15,85\end{array}$} & \multirow{2}{*}{\begin{tabular}{c|}
$\begin{array}{c}\text { Renda média } \\
\text { inferior }\end{array}$ \\
17,59
\end{tabular}} & \multirow{2}{*}{\begin{tabular}{r|}
$\begin{array}{c}\text { Renda média } \\
\text { superior }\end{array}$ \\
20,68
\end{tabular}} & \multirow{2}{*}{$\begin{array}{r}\begin{array}{c}\text { Alta renda } \\
\text { não-OCDE }\end{array} \\
18,14\end{array}$} & \multirow{2}{*}{$\begin{array}{c}\begin{array}{c}\text { Alta renda } \\
\text { OCDE }\end{array} \\
20,56\end{array}$} \\
\hline \multirow{4}{*}{ FBK } & Média & & & & & \\
\hline & D.P & 3,72 & 5,01 & 5,25 & 4,28 & 3,68 \\
\hline & Mín & 9,16 & 7,26 & 14,71 & 12,42 & 11,65 \\
\hline & Máx & 21,58 & 27,17 & 37,54 & 27,00 & 30,79 \\
\hline \multirow{4}{*}{ OPEN } & Média & 53,14 & 67,37 & 86,09 & 126,03 & 65,81 \\
\hline & D.P & 14,82 & 29,50 & 40,79 & 79,66 & 27,18 \\
\hline & Mín & 31,06 & 25,60 & 21,10 & 46,29 & 22,97 \\
\hline & Máx & 84,67 & 148,70 & 171,58 & 354,67 & 141,92 \\
\hline \multirow{4}{*}{ IDE } & Média & 1,76 & 2,69 & 4,03 & 6,26 & 2,64 \\
\hline & D.P & 1,36 & 2,21 & 3,15 & 4,71 & 1,90 \\
\hline & Mín & 0,37 & 0,90 & 0,86 & 1,52 & 0,11 \\
\hline & Máx & 5,32 & 9,12 & 12,45 & 15,20 & 9,31 \\
\hline \multirow{4}{*}{ DF } & Média & 14,00 & 24,04 & 46,59 & 60,99 & 94,18 \\
\hline & D.P & 7,19 & 10,91 & 29,99 & 34,77 & 25,69 \\
\hline & Mín & 3,83 & 6,96 & 12,37 & 27,44 & 51,30 \\
\hline & Máx & 25,46 & 41,20 & 111,17 & 145,98 & 149,05 \\
\hline \multirow{4}{*}{ PIBpcinicial } & Média & 386,69 & $1.199,39$ & $4.520,07$ & $13.947,45$ & $30.525,37$ \\
\hline & D.P & 118,77 & 553,66 & $1.923,01$ & $5.635,36$ & $10.920,29$ \\
\hline & Mín & 216,68 & 471,55 & $1.374,79$ & $5.116,86$ & $6.338,01$ \\
\hline & Máx & 626,62 & $2.429,63$ & $10.582,36$ & $24.214,25$ & $51.951,32$ \\
\hline
\end{tabular}

Fonte: Elaboração própria a partir dos dados do Banco Mundial.

Nota: (1) Estatísticas descritivas calculadas a partir das médias temporais dos países, para o período de 1985 a 2013; (2) FBK é o investimento doméstico descontadas as entradas líquidas de investimento direto estrangeiro. 
Na Tabela 1, observa-se ainda que os países de renda mais alta, em geral, possuem setores financeiros melhor desenvolvidos. Em média, nos países de alta renda da OCDE, o montante de crédito ofertado pelos bancos para o setor privado corresponde a $94,18 \%$ do PIB, enquanto, nos países de baixa renda, o percentual corresponde somente a $14,00 \%$. Destaca-se também que o menor índice de crédito interno dos bancos para o setor privado no grupo de países da OCDE é igual a 2 vezes o maior índice do grupo de baixa renda e igual a 1,25 vezes o maior índice do grupo de baixa renda inferior.

A partir das médias da renda per capita dos cinco grupos de países, verifica-se que a amostra é bastante heterogênea. As médias temporais da renda per capita dos países variam num intervalo de US\$216,68 (Malawi) a US\$ 51.951,32 (Suíça). Além disso, a variabilidade da renda per capita é maior nos grupos de alta renda. É importante destacar que essa heterogeneidade da amostra é fundamental para o estudo, visto que um dos objetivos deste artigo é verificar se o impacto da abertura comercial e financeira depende do nível de renda alcançado pelos países.

Da análise acima, observa-se que os países de alta renda e de renda média superior, em geral, apresentam maiores valores médios de investimento doméstico, abertura comercial e abertura financeira, além de possuírem setores financeiros melhor desenvolvidos. Por outro lado, os países de baixa renda ou renda média inferior possuem, em média, níveis mais baixos de formação bruta de capital, comércio e entrada líquida de recursos estrangeiros. Sendo assim, é relevante investigar se a direção e a magnitude do efeito do comércio e da abertura financeira sobre o investimento doméstico estão condicionados ao nível de renda e de desenvolvimento financeiro dos países.

\section{Resultados}

Os parâmetros estimados do modelo linear, Equação (1), estão apresentados na Tabela 2. O modelo foi estimado por MQ2E, usando o estimador de efeitos fixos, apontado pelo teste de especificação de Hausman como o mais apropriado. Nos resultados reportados, as variáveis explicativas endógenas defasadas em um período e as outras variáveis explicativas exógenas foram utilizadas como instrumentos. Destaca-se que o uso de mais defasagens das variáveis explicativas endógenas produz resultados semelhantes 
aos apresentados na Tabela 2. Além disso, o teste de restrições de sobreidentificações de Hansen-Sargan indica não rejeição da hipótese de validade dos instrumentos. ${ }^{6}$ Por sua vez, o teste $\mathrm{F}$ aponta que os instrumentos são conjuntamente significantes nas regressões de $1^{\circ}$ estágio para OPEN e IDE.

Nesse caso linear, observa-se que o efeito do comércio sobre o investimento doméstico é significante e positivo, enquanto o IDE tem efeito significante e negativo sobre a formação bruta de capital. Além disso, o parâmetro estimado da variável renda per capita inicial foi significante ao nível de $1 \%$, mas não apresentou o sinal esperado. Conforme a estimativa, um aumento na renda per capita inicial reduziria o investimento doméstico do país. Por sua vez, o efeito estimado da medida de desenvolvimento financeiro sobre a formação bruta de capital foi significante e positivo. Destacase que é importante investigar se esses efeitos estimados do comércio e do IDE são invariantes ao nível de desenvolvimento dos países. Desse modo, a seguir investiga-se a presença de efeito limiar e não-linearidades nas relações entre investimento doméstico, comércio e IDE.

Tabela 2 - Efeitos do comércio e do IDE sobre o investimento, modelo linear

\begin{tabular}{|c|c|}
\hline Variável dependente: FBK & $\beta$ \\
\hline OPEN $_{i t}$ & $\begin{array}{l}0,0471^{*} \\
(0,0073)\end{array}$ \\
\hline $\mathrm{IDE}_{\mathrm{it}}$ & $\begin{array}{l}-0,3248^{*} \\
(0,0575)\end{array}$ \\
\hline PIBpcinicial $_{i t}$ & $\begin{array}{l}-0,0004^{*} \\
(0,0000)\end{array}$ \\
\hline $\mathrm{DF}_{i t}$ & $\begin{array}{c}0,0225^{*} \\
(0,0057)\end{array}$ \\
\hline Constante & $\begin{array}{c}20,3557^{*} \\
(0,5841)\end{array}$ \\
\hline $\mathrm{R}^{2}$ within & 0,2050 \\
\hline p-valor (Wald) & 0,0000 \\
\hline Teste de Hausman ( $p$-valor) & 0,0000 \\
\hline F: OPEN & $1798,05^{* *}$ \\
\hline F: IDE & 253,66 ** \\
\hline Observações & 2380 \\
\hline $\begin{array}{l}\text { Cross-section } \\
\text { Instrumentos } \\
\text { OPEN }_{t-1} ; \text { IDE }_{t-1} ; \text { PIBpcinicial; DF }\end{array}$ & 85 \\
\hline
\end{tabular}

Fonte: Elaboração própria.

Nota: O modelo (1) foi estimado pelo método de MQ2E. Os erros padrão são reportados entre parênteses; *, ** $\mathrm{e}^{* * *}$ indicam significância ao nível de $1 \%, 5 \%$ e $10 \%$, respectivamente; + indica não significância.

${ }_{6}$ Por exemplo, para o caso em que os instrumentos são OPEN $\mathrm{t}_{\mathrm{t}-1}, \mathrm{OPEN}_{\mathrm{t}-2}, \mathrm{IDE}_{\mathrm{t}-1}, \mathrm{IDE}_{\mathrm{t}-2}, \mathrm{PIB}_{\text {pcinicial }}$ e DF, a estatística de Sargan-Hansen é 4,179 e o p-valor, 0,1237. Se $\operatorname{OPEN}_{\mathrm{t}-3}$ e $\mathrm{OPEN}_{\mathrm{t}-4}$ são acrescentados à lista de instrumentos, a estatística de Sargan-Hansen é 5,640 e o p-valor, 0,2277. 
Tabela 3 - Efeitos threshold do comércio e do IDE sobre o investimento doméstico

\begin{tabular}{|c|c|c|}
\hline Variável threshold $\left(q_{i t}\right)$ & $\mathrm{DF}_{\text {it }}$ & PIBpcinicial $_{i t}$ \\
\hline \multicolumn{3}{|l|}{ Threshold estimado } \\
\hline$\hat{\gamma}$ & 45,00 & 707,87 \\
\hline Intervalo de confiança de $95 \%$ & {$[43,40-46,12]$} & {$[536,94-1.209,28]$} \\
\hline \multicolumn{3}{|l|}{ Regressores dependentes do regime } \\
\hline \multicolumn{3}{|l|}{$q_{i t} \leq \hat{\gamma}$} \\
\hline OPEN $_{\text {it }}$ & $\begin{array}{l}2,1961^{*} \\
(0,0887)\end{array}$ & $\begin{array}{c}3,6277^{*} \\
(0,0506)\end{array}$ \\
\hline \multirow[t]{2}{*}{$I E_{i t}$} & $-1,1044^{*}$ & $-0,5037^{*+}$ \\
\hline & $(0,2706)$ & $(0,2253)$ \\
\hline \multirow[t]{2}{*}{ Constante } & $-1,7057^{*}$ & $-2,7417^{*}$ \\
\hline & $(0,4219)$ & $(0,5026)$ \\
\hline \multicolumn{3}{|l|}{$q_{i t}>\hat{\gamma}$} \\
\hline OPEN $_{i t}$ & $\begin{array}{l}2,1149^{*} \\
(0,0938)\end{array}$ & $\begin{array}{c}1,5347^{*} \\
(0,1417)\end{array}$ \\
\hline $\mathrm{IDE}_{i t}$ & $\begin{array}{c}-0,7624^{* * *+} \\
(0,4225)\end{array}$ & $\begin{array}{l}-0,7713^{*} \\
(0,2118)\end{array}$ \\
\hline \multicolumn{3}{|l|}{ Regressores independentes do regime } \\
\hline PIBpcinicial $_{\text {it }}$ & $\begin{array}{l}-0,0042^{*} \\
(0,0001)\end{array}$ & $\begin{array}{l}-0,0030^{*} \\
(0,0003)\end{array}$ \\
\hline \multirow[t]{2}{*}{$\mathrm{DF}_{i t}$} & $0,0137^{+}$ & $0,0162^{+}$ \\
\hline & $(0,0101)$ & $(0,0115)$ \\
\hline Observações & 2595 & 2595 \\
\hline Cross-section & 95 & 95 \\
\hline \multicolumn{3}{|l|}{ Instrumentos } \\
\hline $\begin{array}{l}\text { OPEN }_{i t} \\
\text { IDE }_{i t}\end{array}$ & $\begin{array}{c}\mathrm{OPEN}_{i, t-1} \\
\mathrm{IDE}_{i, t-1}\end{array}$ & $\begin{array}{l}\text { OPEN }_{i, t-1} \\
\text { IDE }_{i, t-1}\end{array}$ \\
\hline
\end{tabular}

Fonte: Elaboração própria.

Nota: A variável dependente é investimento doméstico. O modelo (2) foi estimado usando uma adaptação do código de Kremer, Bick e Nautz (2013). Os erros padrão são reportados entre parênteses; * , ** e *** indicam significância ao nível de $1 \%, 5 \%$ e 10\%, respectivamente; + indica não significância.

Os resultados da estimação dos efeitos do comércio e do IDE sobre o investimento doméstico, considerando o desenvolvimento financeiro como variável threshold, estão apresentados na segunda coluna da Tabela 3. O valor threshold estimado da proxy de desenvolvimento financeiro é 45, indicando que a amostra pode ser dividida num grupo de países de baixo desenvolvimento financeiro, em que $\mathrm{DF} \leq 45$, e num grupo de países com setores financeiros mais desenvolvidos, em que DF $>45$. Além disso, para um nível de confiança de 95\%, o intervalo do valor threshold estimado varia de 43,40 a 46,12. Esse intervalo pode ser derivado do Gráfico 1 a partir de $L R_{n}(\gamma)$ para os valores de $\gamma$ em que a razão de verossimilhança fica abaixo da linha tracejada (95\% Critical). Ademais, destaca-se que no Gráfico 1 parece não haver outro valor da estatística de teste significante indicando 
um segundo valor limiar. Seria mais apropriado testar a existência de um número de regimes superior a 2 , entretanto, este trabalho tem a limitação de investigar a significância de um único threshold.

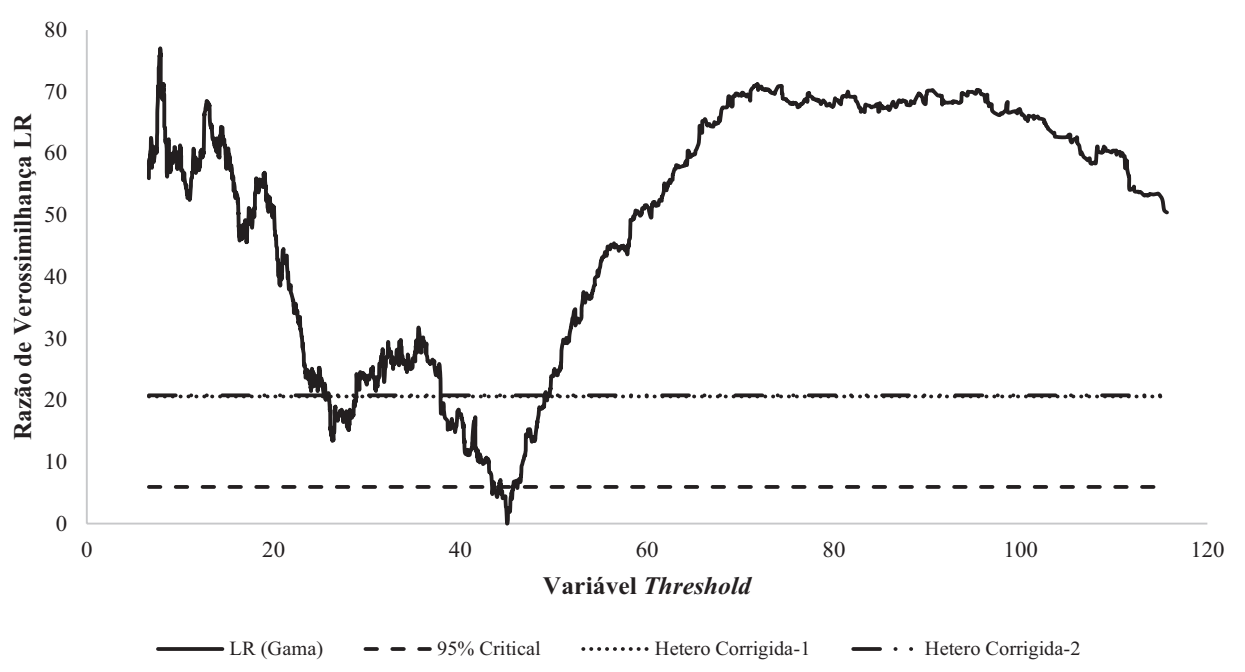

Gráfico 1 - Construção do intervalo de confiança no modelo de um único threshold de desenvolvimento financeiro

Fonte: Elaboração própria.

Nos dois regimes, o coeficiente da variável explicativa comércio é positivo e estatisticamente significante ao nível de 5\%. Um aumento de uma unidade na medida de comércio está associado a um aumento de 2,2 (2,1) no investimento doméstico no regime de baixo (alto) desenvolvimento financeiro. Por outro lado, o coeficiente do investimento direto estrangeiro é negativo e estatisticamente significante no regime de baixo desenvolvimento financeiro, mas estatisticamente insignificante no regime de alto desenvolvimento financeiro, ambos ao nível de 5\%. Para o grupo de países com nível de DF menor que 45, um aumento de uma unidade na medida de abertura financeira produz, em média, uma redução de 1,1 no investimento doméstico. Esses resultados sugerem que, independentemente do nível de desenvolvimento financeiro, os países se beneficiam da abertura comercial, uma vez que o comércio facilita o acesso a bens de capital e insumos estrangeiros (em geral, mais baratos), implicando redução do custo do capital e estímulo ao investimento. 
Por outro lado, os parâmetros estimados indicam que o IDE impacta negativamente o investimento doméstico dos países cujos setores financeiros são menos desenvolvidos. Conforme previsto na literatura, esse efeito substituição do IDE pode ocorrer nos países com baixo desenvolvimento financeiro se, para financiarem seus projetos, as firmas estrangeiras disputarem com as firmas domésticas os recursos do mercado de crédito local. Isso produziria um aumento da taxa de juros e, consequentemente, uma redução do investimento doméstico. Por sua vez, ao nível de significância de 5\%, o IDE não afeta o investimento doméstico no regime de alto desenvolvimento financeiro.

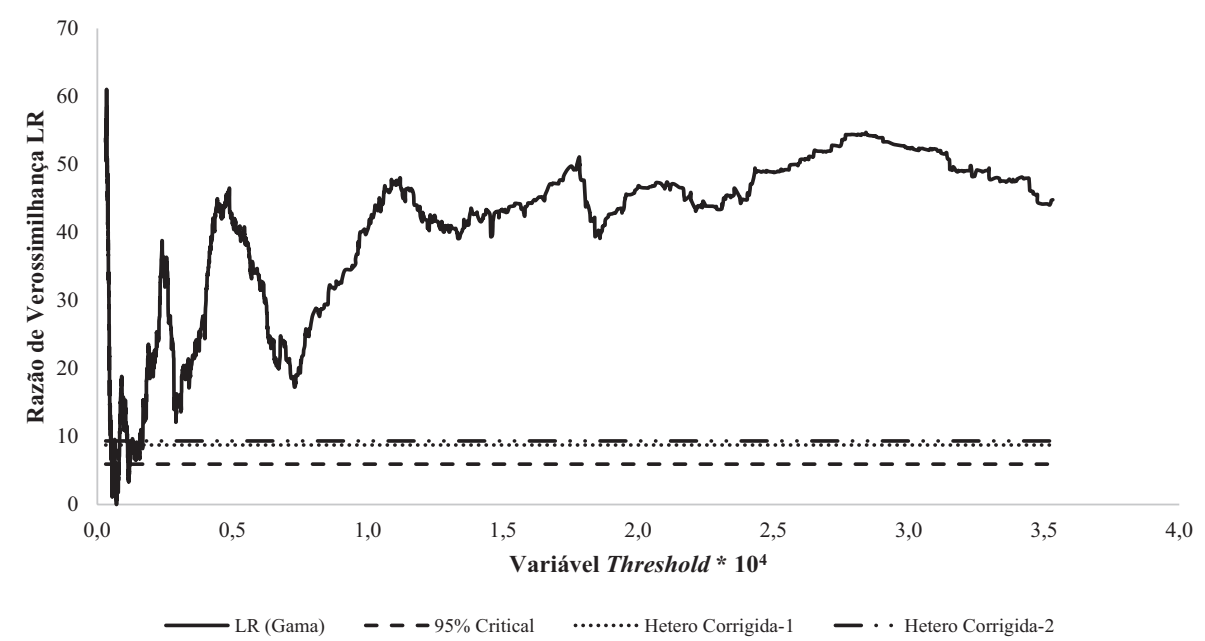

Gráfico 2 - Construção do intervalo de confiança no modelo de um único threshold de PIB per capita

Fonte: Elaboração própria.

A Equação (2) também foi estimada considerando a renda per capita inicial como variável threshold. Os resultados estão apresentados na terceira coluna da Tabela 3. O valor estimado do threshold da renda na regressão do investimento doméstico é 707,87 (em US\$ de 2005). Ademais, o intervalo de 95\% de confiança para o threshold estimado é de 536,94 - 1.209,28. É importante ressaltar que, no Gráfico 2, além da queda da razão de verossimilhança em $\hat{\gamma}=707,87$, observam-se outros dois declives próximos aos valores de renda de $2.500,00$ e de $7.500,00$. Tal comportamento pode sugerir a existência de mais thresholds na regressão. 
Considerando o valor threshold estimado, os coeficientes indicam que o impacto da abertura comercial sobre o investimento doméstico é estatisticamente significante e positivo nos regimes de baixa e alta renda. O comércio pode favorecer a formação bruta de capital dos países, por exemplo, ao permitir maior acesso a bens de capital e a insumos importados, ao ampliar o tamanho do mercado para os produtores e ao possibilitar os spillovers de conhecimento. Os resultados apontam ainda que esses efeitos positivos do comércio parecem ser maiores nos países com PIB per capita inferior a 707,87. No regime de baixa renda, um aumento de uma unidade na medida de abertura comercial eleva, em média, em 3,63 a formação bruta de capital; enquanto, no regime de alta renda, um aumento de uma unidade na medida do comércio está associado a um aumento de 1,53 no investimento doméstico.

Além disso, os resultados sugerem que o IDE atua como substituto do investimento doméstico em ambos os regimes de renda. Um aumento de uma unidade na proxy de abertura financeira leva a uma redução de 0,5 no investimento doméstico no regime de baixa renda e a uma diminuição de 0,77 no investimento dos países de renda per capita superior a 707,87. Essa substituição entre os investimentos pode ser resultado de distorções geradas por oferta de incentivos à atração de IDE, que modificam os retornos relativos dos tipos de investimento doméstico, ou também porque o IDE tem acesso a melhores tecnologias e melhor gestão dos negócios, conforme estudos discutidos na Seção 2. Ademais, como destaca de Mello (1999), o grau de substituição entre os dois tipos de investimento parece ser maior em economias tecnologicamente avançadas, porque a taxa de obsolescência do capital doméstico, na presença de IDE, parece ser crescente nas economias avançadas ou porque as economias menos desenvolvidas são menos eficientes no uso das novas tecnologias agregadas ao IDE.

Em suma, os resultados indicam que o comércio contribui positivamente para o investimento doméstico nos dois regimes, tanto na regressão em que a medida de desenvolvimento financeiro é a variável limiar como no caso em que essa variável é a renda per capita inicial. Por outro lado, o IDE parece afetar negativamente o investimento doméstico em ambos os regimes de renda e nos países de baixo desenvolvimento financeiro. 


\section{Considerações finais}

Neste artigo, investigou-se a existência de efeitos threshold de renda e de desenvolvimento financeiro na determinação dos impactos do comércio e do investimento direto estrangeiro sobre o investimento doméstico. Para tanto, procedeu-se a uma adaptação do modelo threshold de painel de Kremer, Bick e Nautz (2013), o que permitiu realizar o estudo a partir de uma base de dados mais ampla que a utilizada em Kim, Lin e Suen (2013), que baseiam-se na abordagem de Caner e Hansen (2004) de regressão threshold com variável instrumental para dados em cross section. Além disso, a modificação do modelo de Kremer, Bick e Nautz (2013) permitiu considerar neste estudo duas variáveis explicativas endógenas dependentes do regime.

Em síntese, os resultados sugerem que o comércio afeta positivamente o investimento doméstico nos dois regimes, tanto quando se considera threshold de desenvolvimento financeiro como quando se levam em conta threshold de renda per capita inicial. Além disso, os coeficientes estimados indicam que os benefícios da abertura comercial são maiores nos países de baixa renda. Por outro lado, o IDE parece afetar negativamente o investimento doméstico em ambos os regimes de renda e nos países de baixo desenvolvimento financeiro. É importante ressaltar, todavia, que este estudo limita-se a estimar e testar a significância de um valor threshold, que divide a amostra de países em dois regimes. Sendo assim, uma forma de dar continuidade ao presente estudo consiste em ampliar o número de possíveis regimes.

\section{Referências}

Baldwin, Richard E., and Elena Seghezza. 1996. "Testing for trade-induced, investment-led growth." NBER Working Paper No. W5416.

Barro, Robert J., and Xavier I. Sala-i-Martin. 2004. Economic Growth. 2a ed. Londres: MIT Press.

Billor, Nedret, Ali S. Hadi and Paul F. Velleman. 2000. "BACON: blocked adaptive computationally efficient outlier nominators." Computational Statistics \& Data Analysis 34: 279-298.

Caner, Mehmet, and Bruce E. Hansen. 2004. “Instrumental Variable Estimation of a Threshold Model.” Econometric Theory 20: 813-843. doi:10.1017/S0266466604205011.

Carrasco, Marine. 2002. "Misspecified Structural Change, Threshold, and Markov-switching models.” Journal of Econometrics 109: 239-273. 
Easterly, William. 1993. "How much do distortions affect growth?” Journal of Monetary Economics 32 (2): 187-212.

Eicher, Theo S. 1999. "Trade, development and converging growth rates: Dynamic gains from trade reconsidered." Journal of International Economics 48 (1): 179-198.

Feldstein, Martin. 2000. “Aspects of global economic integration: Outlook for the future.” NBER Working Paper No. 7899.

Hansen, Bruce E. 1999. "Threshold effects in non-dynamic panels: Estimation, testing, and inference.” Journal of Econometrics 93: 345-368.

Hansen, Bruce E. 2000. "Sample Splitting and Threshold Estimation.” Econometrica 68 (3): 575-603.

Harrison, Ann E. 1996. "Openness and growth: A time-series, cross-country analysis for developing countries." Journal of Development Economics 48 (2): 419-447.

Kim, David Deok-Ki, and Jung-Soo Seo. 2003. "Does FDI inflow crowd out domestic investment in Korea?" Journal of Economic Studies 30 (6): 605-622.

Kim, Dong-Hyeon, Shu-Chin Lin and Yu-Bo Suen. 2013. "Investment, trade openness and foreign direct investment: Social capability matters." International Review of Economics and Finance 26: 56-69.

Kremer, Stephanie, Alexander Bick and Dieter Nautz. 2013. "Inflation and growth: new evidence from a dynamic panel threshold analysis." Empirical Economics 44: 861-878.

Lean, Hooi Hooi, and Bee Wah Tan. 2011. "Linkages between Foreign Direct Investment, Domestic Investment and Economic Growth in Malaysia." Journal of Economic Cooperation and Development 32 (4): 75-96.

Lee, Jong-Wha. 1995. "Capital goods imports and long-run growth.” Journal of Development Economics 48 (1): 91-110.

Levine, Ross, and David Renelt. 1992. "A sensitivity analysis of cross-country growth regressions.” The American Economic Review 82 (4): 942-963.

Mello Jr., L. R. de. 1999. "Foreign direct investment-led growth: Evidence from time series and panel data." Oxford Economic Papers 51 (1): 133-151. doi:10.1093/oep/51.1.133.

Rebelo, Sergio. 1991. "Long-Run Policy Growth Analysis and Long-Run Growth.” The Journal of Political Economy 99 (3): 500-521.

Van Loo, Frances. 1977. "The effect of foreign direct investment on investment in Canada." The Review of Economics and Statistics 59 (4): 474-481. doi:10.2307/1928712.

Wacziarg, Romain. 2001. "Measuring the dynamic gains from trade." The World Bank Economic Review 15 (3): 393-429.

Wang, Miao. 2010. "Foreign direct investment and domestic investment in the host country: evidence from panel study." Applied Economics 42 (29).

Wen, Mei. 2007. "Foreign direct investment, regional market conditions and regional development: A panel study on China." The Economics of Transition 15 (1): 125-151. doi:10.1111/j.1468-0351.2007.00274.x.

Wooldridge, Jeffrey M. 2002. "Econometric Analysis of Cross Section and Panel Data.” Londres: MIT Press. 
APÊNDICE A - CONJUNTO DE DADOS DE 95 PAÍSES NO PERÍODO DE 1985 A 2013

\begin{tabular}{|c|c|c|c|c|c|c|c|c|}
\hline \multirow{2}{*}{ Código } & \multirow{2}{*}{ País } & \multirow{2}{*}{ Classificação } & \multirow{2}{*}{ № de períodos } & \multicolumn{5}{|c|}{ Média } \\
\hline & & & & FBK & OPEN & IDE & PIBpcinicial & DF \\
\hline 1 & Antígua e Barbuda & Alta renda: não OCDE & 29 & 22,16 & 143,16 & 10,65 & $10.651,51$ & 59,55 \\
\hline 2 & Argentina & Renda média superior & 22 & 15,35 & 23,06 & 2,01 & $5.045,51$ & 18,23 \\
\hline 3 & Austrália & Alta renda: OCDE & 29 & 24,02 & 38,00 & 2,59 & $29.860,80$ & 85,34 \\
\hline 4 & Áustria & Alta renda: OCDE & 29 & 22,39 & 81,85 & 2,63 & $34.262,66$ & 99,02 \\
\hline 5 & Bahamas & Alta renda: não OCDE & 29 & 22,13 & 99,89 & 3,62 & $21.981,35$ & 54,74 \\
\hline 6 & Bahrein & Alta renda: não OCDE & 28 & 17,19 & 152,86 & 5,58 & $16.910,66$ & 47,03 \\
\hline 7 & Bangladesh & Renda baixa & 29 & 21,29 & 31,06 & 0,42 & 372,63 & 25,46 \\
\hline 8 & Barbados & Alta renda: não OCDE & 25 & 12,42 & 91,56 & 2,23 & $12.896,83$ & 50,71 \\
\hline 9 & Benim & Renda baixa & 29 & 16,43 & 51,05 & 1,59 & 505,78 & 17,09 \\
\hline 10 & Bolívia & Renda média inferior & 29 & 12,33 & 56,93 & 3,72 & 977,65 & 39,23 \\
\hline 11 & Botsuana & Renda média superior & 29 & 27,14 & 97,96 & 2,81 & $4.683,01$ & 16,75 \\
\hline 12 & Brasil & Renda média superior & 29 & 16,91 & 21,10 & 2,01 & $4.595,82$ & 50,28 \\
\hline 13 & Burquina Faso & Renda baixa & 29 & 21,58 & 38,67 & 0,60 & 355,32 & 13,96 \\
\hline 14 & Camarões & Renda média inferior & 29 & 16,91 & 41,81 & 1,10 & 952,00 & 13,69 \\
\hline 15 & Canadá & Alta renda: OCDE & 24 & 18,86 & 64,95 & 2,40 & $30.881,50$ & 89,74 \\
\hline 16 & $\begin{array}{l}\text { República da África } \\
\text { Central }\end{array}$ & Renda baixa & 28 & 10,35 & 41,69 & 1,05 & 372,35 & 6,62 \\
\hline 17 & Chade & Renda baixa & 29 & 15,64 & 63,83 & 5,32 & 498,95 & 5,78 \\
\hline 18 & Chile & Alta renda: OCDE & 29 & 17,76 & 62,93 & 5,50 & $6.338,01$ & 57,87 \\
\hline 19 & China & Renda média superior & 29 & 37,54 & 43,16 & 3,38 & $1.374,79$ & 102,59 \\
\hline 20 & $\begin{array}{l}\text { República do } \\
\text { Congo }\end{array}$ & Renda média inferior & 29 & 16,00 & 118,68 & 9,12 & $1.757,86$ & 9,91 \\
\hline 21 & Costa Rica & Renda média superior & 29 & 16,36 & 81,59 & 3,66 & $4.143,26$ & 26,38 \\
\hline 22 & Costa do Marfim & Renda média inferior & 29 & 10,58 & 76,74 & 1,40 & $1.064,75$ & 21,51 \\
\hline 23 & Chipre & Alta renda: não OCDE & 26 & 17,74 & 101,12 & 4,74 & $19.181,55$ & 145,98 \\
\hline 24 & Dinamarca & Alta renda: OCDE & 29 & 18,92 & 79,74 & 2,29 & $43.297,48$ & 105,87 \\
\hline 25 & Dominica & Renda média superior & 29 & 16,07 & 102,64 & 7,61 & $4.779,75$ & 48,28 \\
\hline 26 & $\begin{array}{l}\text { República Domi- } \\
\text { nicana }\end{array}$ & Renda média superior & 29 & 18,58 & 70,91 & 2,94 & $3.217,83$ & 23,91 \\
\hline 27 & Equador & Renda média superior & 29 & 21,79 & 49,90 & 1,43 & $2.883,73$ & 19,10 \\
\hline 28 & $\begin{array}{l}\text { República Árabe } \\
\text { do Egito }\end{array}$ & Renda média inferior & 29 & 18,46 & 50,16 & 2,48 & $1.127,34$ & 37,67 \\
\hline 29 & El Salvador & Renda média inferior & 29 & 14,05 & 60,98 & 1,57 & $2.429,63$ & 35,71 \\
\hline 30 & Fiji & Renda média superior & 24 & 14,71 & 116,20 & 3,89 & $3.147,73$ & 38,62 \\
\hline 31 & Finlândia & Alta renda: OCDE & 29 & 21,50 & 65,79 & 2,15 & $33.094,59$ & 71,78 \\
\hline 32 & França & Alta renda: OCDE & 29 & 20,15 & 48,77 & 1,79 & $31.541,69$ & 90,61 \\
\hline 33 & Gabão & Renda média superior & 29 & 26,93 & 91,29 & 0,86 & $6.764,73$ & 12,37 \\
\hline 34 & Alemanha & Alta renda: OCDE & 29 & 20,58 & 59,05 & 1,34 & $32.586,28$ & 99,32 \\
\hline
\end{tabular}




\begin{tabular}{|c|c|c|c|c|c|c|c|c|}
\hline \multirow{2}{*}{ Código } & \multirow{2}{*}{ País } & \multirow{2}{*}{ Classificação } & \multirow{2}{*}{ № de períodos } & \multicolumn{5}{|c|}{ Média } \\
\hline & & & & FBK & OPEN & IDE & PIBpcinicial & DF \\
\hline 35 & Gana & Renda média inferior & 29 & 17,74 & 71,32 & 2,98 & 471,55 & 9,60 \\
\hline 36 & Grécia & Alta renda: OCDE & 29 & 23,09 & 47,14 & 0,84 & $18.599,76$ & 57,72 \\
\hline 37 & Granada & Renda média superior & 29 & 22,75 & 97,01 & 9,24 & $5.152,55$ & 61,20 \\
\hline 38 & Guatemala & Renda média inferior & 29 & 14,55 & 51,49 & 1,54 & $2.021,75$ & 20,84 \\
\hline 39 & Honduras & Renda média inferior & 29 & 23,11 & 98,97 & 3,49 & $1.296,80$ & 37,50 \\
\hline 40 & Islândia & Alta renda: OCDE & 29 & 19,14 & 74,92 & 2,38 & $48.259,60$ & 92,58 \\
\hline 41 & Índia & Renda média inferior & 29 & 27,17 & 29,57 & 0,90 & 628,72 & 32,49 \\
\hline 42 & Indonésia & Renda média inferior & 29 & 26,91 & 54,72 & 0,97 & $1.152,01$ & 33,04 \\
\hline 43 & Irlanda & Alta renda: OCDE & 29 & 11,65 & 141,92 & 9,31 & $36.896,77$ & 105,99 \\
\hline 44 & Israel & Alta renda: OCDE & 27 & 19,01 & 75,83 & 2,23 & $17.808,75$ & 71,95 \\
\hline 45 & Itália & Alta renda: OCDE & 29 & 20,07 & 45,28 & 0,63 & $28.964,49$ & 74,00 \\
\hline 46 & Japão & Alta renda: OCDE & 29 & 25,57 & 22,97 & 0,11 & $33.177,04$ & 142,00 \\
\hline 47 & Jordânia & Renda média superior & 29 & 21,49 & 121,93 & 4,93 & $2.191,53$ & 70,37 \\
\hline 48 & Quénia & Renda baixa & 29 & 19,08 & 56,31 & 0,55 & 535,77 & 23,62 \\
\hline 49 & $\begin{array}{l}\text { República da } \\
\text { Coréia }\end{array}$ & CDE & 29 & 30,79 & 69,67 & 0,72 & $14.716,46$ & 84,82 \\
\hline 50 & Madagascar & Renda baixa & 29 & 13,77 & 56,53 & 3,06 & 289,72 & 12,37 \\
\hline 51 & Malawi & Renda baixa & 29 & 17,64 & 66,54 & 1,59 & 216,68 & 9,24 \\
\hline 52 & Malásia & Renda média superior & 29 & 24,02 & 171,58 & 3,99 & $4.675,50$ & 111,17 \\
\hline 53 & Mali & Renda baixa & 28 & 19,64 & 60,55 & 2,32 & 389,80 & 15,76 \\
\hline 54 & Malta & Alta renda: não OCDE & 27 & 14,46 & 165,69 & 7,30 & $12.640,12$ & 94,54 \\
\hline 55 & Maurício & Renda média superior & 29 & 24,34 & 123,20 & 1,68 & $4.379,95$ & 58,35 \\
\hline 56 & México & Renda média superior & 29 & 19,42 & 47,33 & 2,14 & $7.322,26$ & 17,79 \\
\hline 57 & Holanda & Alta renda: OCDE & 29 & 17,86 & 119,33 & 4,14 & $36.922,53$ & 120,37 \\
\hline 58 & Nova Zelândia & Alta renda: OCDE & 26 & 18,43 & 58,41 & 3,16 & $23.672,74$ & 95,32 \\
\hline 59 & Nicarágua & Renda média inferior & 29 & 19,70 & 66,95 & 3,62 & $1.088,54$ & 20,80 \\
\hline 60 & Níger & Renda baixa & 29 & 14,84 & 46,92 & 2,81 & 278,79 & 9,64 \\
\hline 61 & Nigéria & Renda média inferior & 29 & 7,26 & 55,18 & 3,46 & 685,63 & 14,82 \\
\hline 62 & Omã & Alta renda: não OCDE & 28 & 19,39 & 84,67 & 1,60 & $12.299,71$ & 31,99 \\
\hline 63 & Paquistão & Renda média inferior & 29 & 16,80 & 34,23 & 1,07 & 617,06 & 24,31 \\
\hline 64 & Panamá & Renda média superior & 28 & 16,38 & 153,20 & 4,82 & $4.285,86$ & 69,48 \\
\hline 65 & Peru & Renda média superior & 29 & 17,28 & 35,98 & 3,09 & $2.620,91$ & 18,80 \\
\hline 66 & Filipinas & Renda média inferior & 29 & 19,14 & 77,94 & 1,41 & $1.121,36$ & 30,07 \\
\hline 67 & Portugal & Alta renda: OCDE & 29 & 21,66 & 63,79 & 2,59 & $16.560,38$ & 106,41 \\
\hline 68 & Ruanda & Renda baixa & 21 & 14,04 & 31,37 & 0,37 & 236,96 & 8,49 \\
\hline 69 & Arábia Saudita & Alta renda: não OCDE & 29 & 20,37 & 73,28 & 1,52 & $13.426,84$ & 27,44 \\
\hline 70 & Senegal & Renda média inferior & 29 & 16,79 & 63,44 & 1,37 & 720,30 & 22,95 \\
\hline 71 & Seychelles & Renda média superior & 29 & 19,54 & 123,77 & 9,39 & $10.582,36$ & 15,75 \\
\hline 73 & Cingapura & Alta renda: não OCDE & 29 & 16,96 & 354,67 & 13,96 & $24.214,25$ & 93,79 \\
\hline
\end{tabular}




\begin{tabular}{|c|c|c|c|c|c|c|c|c|}
\hline \multirow{2}{*}{ Código } & \multirow{2}{*}{ País } & \multirow{2}{*}{ Classificação } & \multirow{2}{*}{ № de períodos } & \multicolumn{5}{|c|}{ Média } \\
\hline & & & & FBK & OPEN & IDE & PIBpcinicial & DF \\
\hline 74 & África do Sul & Renda média superior & 29 & 17,42 & 51,90 & 1,03 & $5.236,95$ & 62,32 \\
\hline 75 & Espanha & Alta renda: OCDE & 29 & 22,14 & 48,34 & 2,71 & $22.581,22$ & 113,73 \\
\hline 76 & Sri Lanka & Renda média inferior & 29 & 24,05 & 69,94 & 1,16 & $1.085,08$ & 24,94 \\
\hline 77 & $\begin{array}{l}\text { São Cristóvão e } \\
\text { Névis }\end{array}$ & Alta renda: não OCDE & 29 & 27,00 & 109,82 & 15,20 & $9.245,86$ & 60,02 \\
\hline 78 & Santa Lúcia & Renda média superior & 29 & 16,66 & 126,77 & 9,57 & $5.009,75$ & 74,96 \\
\hline 79 & $\begin{array}{l}\text { São Vicente e } \\
\text { Granadinas }\end{array}$ & Renda média superior & 29 & 15,17 & 111,71 & 12,45 & $4.115,78$ & 47,02 \\
\hline 80 & Sudão & Renda média inferior & 29 & 17,04 & 25,60 & 2,39 & 590,65 & 6,96 \\
\hline 81 & Suazilândia & Renda média inferior & 29 & 12,48 & 148,70 & 3,99 & 2.114,08 & 17,93 \\
\hline 82 & Suécia & Alta renda: OCDE & 29 & 19,50 & 73,55 & 3,69 & $37.460,31$ & 73,27 \\
\hline 83 & Suíça & Alta renda: OCDE & 29 & 23,41 & 94,73 & 2,88 & $51.951,32$ & 149,05 \\
\hline 84 & $\begin{array}{l}\text { República Árabe } \\
\text { da Síria }\end{array}$ & Renda média inferior & 23 & 20,47 & 62,88 & 0,90 & $1.355,18$ & 9,70 \\
\hline 85 & Tailândia & Renda média superior & 29 & 27,77 & 106,32 & 2,68 & $2.265,43$ & 103,16 \\
\hline 86 & Togo & Renda baixa & 27 & 14,43 & 84,67 & 2,03 & 400,88 & 20,20 \\
\hline 87 & $\begin{array}{l}\text { Trinidad and } \\
\text { Tobago }\end{array}$ & Alta renda: não OCDE & 24 & 13,72 & 89,40 & 6,31 & $8.803,85$ & 33,84 \\
\hline 88 & Tunísia & Renda média superior & 29 & 22,47 & 89,47 & 2,48 & $2.771,90$ & 55,62 \\
\hline 89 & Turquia & Renda média superior & 29 & 20,31 & 43,84 & 1,02 & $6.171,35$ & 24,82 \\
\hline 90 & Reino Unido & Alta renda: OCDE & 29 & 15,81 & 53,33 & 3,38 & $34.074,28$ & 128,06 \\
\hline 91 & Estados Unidos & Alta renda: OCDE & 29 & 20,55 & 23,31 & 1,32 & $38.574,93$ & 51,30 \\
\hline 92 & Uruguai & Alta renda: não OCDE & 29 & 14,10 & 46,29 & 2,43 & $5.116,86$ & 32,20 \\
\hline 93 & Vanuatu & Renda média inferior & 29 & 17,81 & 98,50 & 7,83 & $1.929,31$ & 41,20 \\
\hline 94 & Venezuela & Renda média superior & 28 & 20,71 & 50,34 & 1,62 & $5.583,47$ & 17,50 \\
\hline 95 & Zimbabwe & Renda baixa & 22 & 13,99 & 64,82 & 0,72 & 626,62 & 23,85 \\
\hline
\end{tabular}

Fonte: Elaboração própria a partir dos dados do Banco Mundial. 
APÊNDICE B - EVOLUÇÃO DO INVESTIMENTO DOMÉSTICO EM CADA UM DOS 98 PAÍSES DA AMOSTRA INICIAL, NO PERÍODO DE 1985 A 2013

$\begin{array}{llllllllll}1 & 2 & 3 & 4 & 5 & 6 & 7 & 8 & 9 & 10\end{array}$
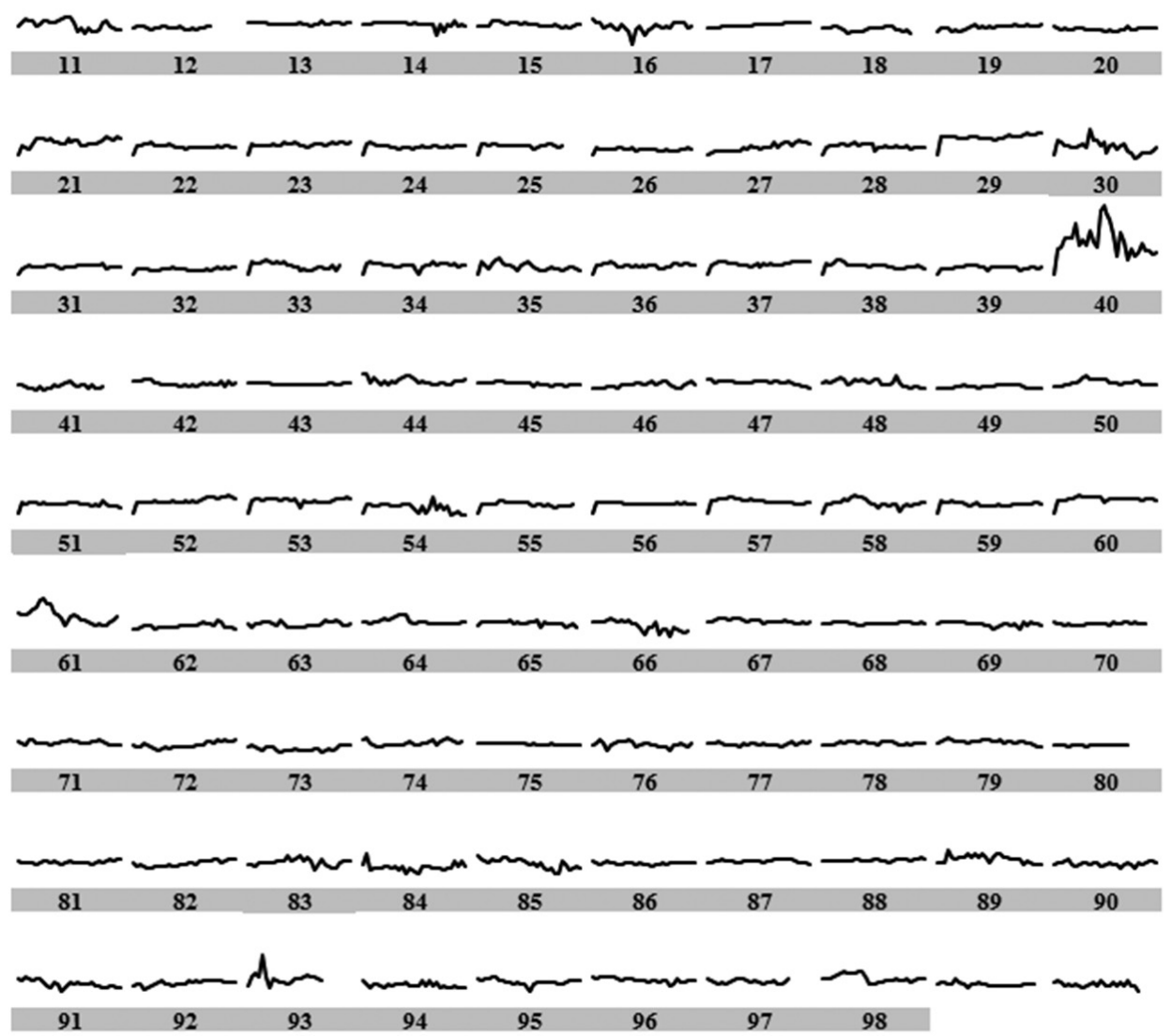

Fonte: Elaboração própria.

Nota: Intervalo do eixo vertical: [-20, 150]. 